AROUEOLOGÍA Y SOCIEDAD

№ 28, 2014: 137-158

ISSN: 0254-8062

RECIBIDO: MARZO DE 2014

ACEPTADO: SETIEMBRE DE 2014

\title{
LA EXPANSIÓN DE LA LENGUA \\ EN LOS ANDES CENTRALES Y LA ESFERA DE INTERACCIÓN CHAVÍN
}

\author{
RICHARD BURGER \\ YALE UNIVERSITY \\ richard.burger@yale.edu
}

RESUMEN

Este artículo considera la posibilidad que la expansion de Aymara fue un resultado de la emergencia y crecimiento del la esfera de interacción Chavín durante el primer milenio antes de Cristo. Alternativas que plantean la expansion del Aymara antes de Chavín durante el Precerámico Tardío (o Arcaico), Periodo Inicial (o Formativo Inferior), o después de Chavín durante el Intermedio Temprano son evaluados y rechazados. También se explora los planteamientos recientes de Paul Heggarty y David Beresford-Jones de «explicaciones sólidas» («strong hypotheses» que intentan de relacionar la expansion de idiomas con fuerzas de la historia como la conquista, migraciones, y expansión agrícola (o de un cultivo clave como el maiz). Se sugiere que estas expliaciones no funcionan en el caso de Aymara, si esta expansión occurió durante el horizonte Chavín, y se ofrece otro modelo basado en la expansion del Sanskrit y la emergencia de la Cosmopolis Sanskrit descrito en los trabajos del linguísta histórica Sheldon Pollock.

Palabras Clave: Expansión de idioma, Aymara, esfera de interacción Chavín, maiz, Cosmopolis Sanskrit.

\begin{abstract}
This article considers the possibility that the expansion of Aymara was the result of the emergence and growth of the Chavin sphere of interaction during the first millennium BC. Alternatives suggesting that the Aymara expansion could have occurred prior to Chavin during the Late Preceramic (Archaic), the Initial Period (Early Formative) or after Chavin during the Early Intermediate Period are examined and rejected. The recent work of Paul Heggarty and David Beresford-Jones is also explored, particularly their ideas on «strong hypotheses» of language expansion that attempt to link such expansion with forces of history such as conquest, migrations and the spread of intensive agriculture (or staples such as maize). It is suggested that these explanations to not seem to work for the case of Aymara, if this expansion occurred during the Chavin horizon, and an alternative model based on the work of historical linguist Sheldon Pollock on the spread of Sanskrit and the emergence of the Sanskrit cosmopolis is presented.
\end{abstract}

KEYwords: Language expansion, Aymara, Chavin interaction sphere, maize, Sanskrit cosmopolis.

\section{ANTECEDENTES}

El problema de la lengua ha sido tratado poco en el estudio de la cultura Chavín por los arqueólogos contemporáneos por lo que no sorprende que, raramente, se haya discutido el rol del fenómeno 
Chavín en la expansión de las lenguas andinas. La regla boasiana en donde cultura, raza y lengua no deben mezclarse ha continuado formando las actitudes de los arqueólogos casi un siglo después de su formulación inicial. Esto es cierto pese al fuerte vínculo que existió entre la lingüística histórica y la arqueología en los comienzos de la arqueología peruana. En 1891 Ernst Middendorf ([1891] 1959), uno de los precursores de la arqueología científica, ya especulaba sobre la historia del aymara y el quechua, y Max Uhle el primer arqueólogo en crear una síntesis coherente de la prehistoria peruana, escribió su disertación doctoral sobre lingüística histórica y más tarde sobre los orígenes del aymara (Uhle 1910; Cerrón-Palomino 1998). Del mismo modo, Julio C. Tello, un quechuahablante nativo, estudió y publicó sobre el arawak y, frecuentemente, reflexionó sobre asuntos de la lengua nativa y su relación con la arqueología (Tello 1913, 1919).

En agudo contraste a estas figuras ancestrales, hoy la mayor parte de los arqueólogos conocen poco sobre lingüística histórica. Esto refleja la historia general de la arqueología en las américas. Mientras John H. Rowe sintió la responsabilidad de enseñar y emprender investigaciones en todos los subcampos de la antropología e hizo contribuciones académicas a la historia del quechua, hay pocos -si hay algunos-arqueólogos contemporáneos con una amplitud comparable (Rowe 1950, 1953. Ver además 1954). La formación inicial de Rowe en los clásicos le dió una sólida base para sus estudios lingüísticos; sin embargo, antecedentes de esta clase son cada vez más escasos entre las jóvenes generaciones. La firme declinación en la competencia lingüística entre los arqueólogos-antropólogos es, en parte, resultado de una disminución en el énfasis sobre la aproximación de los «cuatro campos» en los departamentos de antropología e investigación universitaria de los Estados Unidos. En el Perú, ha tenido un impacto similar la independencia de la arqueología, como disciplina, con respecto a la antropología en la mayoría de las universidades.

En la arqueología andina contemporánea, la convicción generalizada que la lengua sólo puede ser asociada a la prehistoria con gran riesgo ha desaminado a muchos de adquirir la habilidad lingüística necesaria para aplicarla efectivamente. Por el contrario, en el área mesoamericana los actuales esfuerzos por traducir las inscripciones de glifos mayas, oaxaqueños $u$ otros han motivado a los arqueólogos a verse envueltos en el aprendizaje de lenguas nativas y, actualmente, está en curso una activa discusión sobre la distribución y diseminación de lenguajes prehistóricos de un modo que no se ve en los Andes centrales (v.gr. Campbell y Kauffmann 1976; Justeson y Kauffmann 1993). Una notable excepción a estas generalizaciones es el trabajo de Alfredo Torero, quien repetidamente trató de asociar la expansión del lenguaje a los desarrollos culturales prehistóricos (Torero 1974, 1984). Aunque Torero fue un lingüista histórico formado en Francia, fue influenciado por las investigaciones arqueológicas en sus escritos. A pesar de sus mejores esfuerzos, la mayoría de los arqueólogos fueron reticentes a considerar sus conclusiones. Por ello, sus trabajos son raramente citados en la literatura arqueológica.

Afortunadamente, los lingüistas históricos tales como Rodolfo Cerrón-Palomino (2000, 2003), W. Adelaar, Peter Muysken, Ibico Rojas, Gary Parker entre otros, han continuado sus estudios sobre la distribución y diversidad de las lenguas andinas nativas, aunque en gran medida sin la participación de la comunidad arqueológica.

Al mismo tiempo, la caída de la arqueología procesual y la emergencia de una diversidad de propuestas teóricas algunas veces denominadas como arqueología posprocesual, produjo un nuevo consenso en el que algunas preguntas sobre el pasado son tan importantes o interesantes que valen la pena discutirlas, incluso si son ajenas a una investigación científica convencional. Los esfuerzos para ampliar la arqueología del siglo XXI e incluir temas como la cosmología o el género, además de la subsistencia y otros temas, han creado una atmósfera en la cual una reconsideración de la lengua en la prehistoria es menos impactante de lo que fue algunas décadas atrás. Además, la historia cultural de los Andes está mucho más avanzada hoy en día de lo que estuvo en los tiempos de Uhle o Rowe, así, se ha mejorado el potencial para encarar los temas de la expansión del lenguaje. 


\section{La eXPANSión del Lenguaje en los Andes CENTRAles: Hipótesis actuales}

Este ensayo tenía origen en un simposio organizado por un lingüista Paul Heggarty y un arqueólogo, David Beresford-Jones (Heggarty y Beresford-Jones 2010, 2012) en Cambidge University en Inglaterra y los ensayos de los organizadores estimuló este trabajo. Una versión de este trabajo fue presentado en el VII Simposio Enternacional de Arqueologogía PUCP entre el 28 a 30 de agosto de 2009 que tuvo como título "Lenguas y sociedades en el antiguo Perú: Hacia un enfoque interdisciplinario», aunque no llegó a ser incluido en la publicación de este congreso (Kaulicke et al. 2010). A su vez, los trabajos de Heggarty y Beresford-Jones se inspiraron en el trabajo de su mentor Colin Renfrew quien ha servido como pionero en retornar al estudio de la relación entre arqueología y linguística, cuando volvió a reconsiderar la relación entre la arqueología y la lingüística para ayudar a resolver el rompecabezas de los orígenes indoeuropeos (Renfrew 1987; ver además Bellwood 2005). Como resultado de su revisión de la literatura sobre las lenguas nativas de los Andes, Heggarty y Beresford-Jones han llegado a un conjunto de conclusiones básicas que aquí son asumidas como más o menos correctas.

Como se señala en sus trabajos citados, Heggarty y Beresford-Jones creen que dos familias de lenguas sin relación, aymara y quechua, hoy están ampliamente distribuidas en los Andes centrales debido a dos expansiones lingüísticas prehistóricas y que estas expansiones deben ser explicadas en términos de poder, aumento demográfico y fuerzas culturales y políticas. Las bases para postular las dos expansiones han sido establecidas por estudios previos en hablantes de lenguas nativas contemporáneos, documentos históricos y topónimos. En base a la diversidad en estas dos familias lingüísticas, Heggarty y Beresford-Jones infieren que la «profundidad del quechua o el aymara sólo es comparable con la última generación del indoeuropeo. Esto es, la diversidad dentro de cada una de las familias es del mismo orden de magnitud que el de las lenguas romances, de hecho, un poco menos» (Heggarty y Beresford-Jones 2010: 172). Así, en ninguna de las dos familias lingüísticas existen divergencias que, plausiblemente, hayan comenzado hace más de tres mil años.

Heggarty y Beresford-Jones argumentan, además, que cada una de las dos familias lingüísticas, aymara y quechua, fueron inicialmente diseminadas por una sola expansión continua desde sus lugares de origen (Heggarty y Beresford-Jones 2010: Fig. 2). En el caso del aymara, esta primera expansión irradió el aymara central hacia la región norte, centro y surcentral del Perú; una expansión más tardía del aymara en el altiplano de Perú y Bolivia fue la responsable de lo que hoy se conoce como el aymara sureño. En el modelo de Heggarty y Beresford-Jones, la expansión inicial del quechua resultó en la zona continua del quechua, así como también en las avanzadas del quechua en el norte peruano. Expansiones posteriores ocurridas probablemente durante el periodo Inca y Colonial son las responsables de haber producido las variedades más distantes del quechua, como las de Bolivia y Argentina. La idea de dos lenguajes dispersándose y sobreponiéndose, no es nueva. Por ejemplo, la distribución de topónimos aymara fue notada por Max Uhle en el valle de Ica junto con topónimos quechua encontrados en la misma área (Cerrón-Palomino 1998).

En la formulación de Heggarty y Beresford-Jones, se cree que la propagación del aymara precedió a la expansión del quechua. Esta conclusión se basa en múltiples líneas de evidencia lingüística, incluyendo diversidad lingüística, renovación del lenguaje y otros factores fuera de mi alcance crítico como arqueólogo. Desafortunadamente, estos autores no pudieron determinar con precisión cuándo pudo haber ocurrido la expansión del aymara debido a que ellos rechazan el argumento que la glotocronología puede ser usada para asignar fechados absolutos o relativos a dichas ocurrencias. Sin embargo, Heggarty y Beresford-Jones creen que pueden proporcionar gruesas aproximaciones de la profundidad temporal («órdenes de magnitud») comparando el fenómeno andino con otros casos mejor conocidos en el mundo tales como la expansión y diferenciación de las lenguas romance en el Viejo Mundo. Las conclusiones a las que llegan es que una «cronología larga» para el aymara podría ubicar su dispersión alrededor del periodo que va desde los inicios del Horizonte Temprano hasta el temprano/medio Periodo Intermedio Temprano. En contraste, la «cronología larga» estimada para 
el quechua se ubica entre la mitad Horizonte Temprano y los inicios del Horizonte Medio. Así, si el aymara fue la primera de las dos lenguas en diseminarse, bien podría haber ocurrido durante el Horizonte Temprano. Esto plantea la cuestión de si el fenómeno Chavín, también denominado Horizonte Chavín o la Esfera de Interacción Chavín, pudo haber creado las condiciones para esta expansión sin precedentes de la lengua. Esta es la posibilidad que voy a explorar en este ensayo.

\section{El Horizonte Chavín y LA DISPERSión DE LA LENGUA: CONSIDERACIONES TEMPORALES Y GEOGRÁFICAS}

Cuando Julio C. Tello (1942) sugirió que Chavín proporcionó la matriz cultural desde la cual se desarrollaron todas las culturas andinas posteriores, se sabía muy poco sobre la naturaleza de la cultura Chavín y aún menos de los antecedentes de este famoso centro de civilización de la sierra. Afortunadamente, estos retos cronológicos han sido gradualmente superados con excavaciones en sitios tempranos de la costa, sierra y los flancos orientales, así como, con el desarrollo de cronologías relativas basadas en el análisis de las colecciones de cerámica y otros artefactos. Asimismo, la introducción de la técnica del fechado radiocarbónico marcó una enorme diferencia en el control cronológico, a pesar de los problemas de la calibración y la desafortunada presencia del «Hallstatt Plateau» en la mitad del Horizonte Temprano lo cual ha complicado - tanto como aclarado- nuestro actual entendimiento del tema (Higham and Higham 2009: 137 van der Plicht 2004: 45; Zietseva et al. 2005: 99). En cualquier caso, el estado actual de conocimiento de Chavín y sus antecedentes es significativamente más avanzado de lo que fue en los tiempos de Tello e incluso hace 20 años.

Uno de los más notables descubrimientos en las décadas recientes es que muchos de los elementos culturales que caracterizan al centro de Chavín de Huántar tienen sus antecedentes a lo largo de la costa $\mathrm{y}$, en menor grado, en la sierra durante el Periodo Inicial, en el segundo milenio antes de Cristo. En algunos casos, estos antecedentes retroceden hasta el periodo Precerámico Tardío en el tercer milenio antes de Cristo. Este proceso está mejor documentado en los elementos arquitectónicos y estilísticos que fueron sintetizados y transformados en elementos culturales distintivos de Chavín (Burger 1992; Burger y Salazar 2008; Williams 1985). A pesar que las culturas del Precerámico Tardío y el Periodo Inicial fueron las responsables de estos antecedentes estudiados con gran detalle, cada vez es más evidente que estas culturas pre-Chavín fueron bastante provincianas. Sus economías estuvieron basadas en prácticas de subsistencia locales mientras que su intercambio fue limitado, normalmente consistente de productos provenientes de zonas ecológicas complementarias ubicadas en los mismos valles o cuencas. Por ejemplo, en la cuenca de valle de Lurín las comunidades del litoral tuvieron estrechas relaciones con los agricultores del valle bajo quienes, a su vez, tenían conexiones con los campesinos del protegido ambiente de la Chaupiyunga (valle medio) e, igualmente, conexiones más tenues con los agricultores del valle alto. Casi todos sus alimentos y herramientas podían producirse sin la necesidad de contacto más allá de los límites de sus cuencas o valles (Burger y Makowski 2009).

Este patrón es digno de remarcarse debido a que las publicitadas investigaciones del centro Precerámico Tardío de Caral -en el valle medio de Supe- han llevado a algunos a presumir un alto grado de interacción regional la cual, lamentablemente, no está reflejada en los artefactos y ecofactos recuperados en el sitio (Shady 2006). Además, las investigaciones en los valles vecinos de la costa norcentral (Norte Chico) sugiere desarrollos contemporáneos a los observados en Supe. Estas investigaciones debilitan el modelo en el cual la dominación política y económica de Caral se extiende más allá de los límites de su propio valle (Haas y Creamer 2006). En el valle del Chillón, sobre la costa central, existen dos centros del Precerámico Tardío con arquitectura monumental: El Paraíso en el valle bajo y Buena Vista en el valle medio, pero ambos difieren radicalmente uno del otro y ninguno se parece en algo a Caral. Estos recientes descubrimientos refuerzan la impresión de una interacción limitada entre pequeñas entidades políticas autónomas incluso dentro de un mismo valle (Benfer et al. 2010; Quilter 1985). La Tradición Religiosa Kotosh, en la sierra norte del Perú, podría proveer un mejor caso 
de un desarrollo pan-regional pero, aparte de los elementos compartidos de prácticas ceremoniales y arquitectura, las sociedades involucradas parecen haber permanecido relativamente provincianas y en una escala pequeña (Burger 1992: 45-53).

En los últimos 25 años, ha comenzado a ser apreciado el surgimiento de la arquitectura monumental a lo largo de la costa en el segundo milenio antes de Cristo, durante el periodo Inicial, en las culturas de la costa central, norcentral y norte (Burger 1985). Muchas de estas construcciones tales como Sechín Alto en el valle de Casma o San Jacinto en el valle de Chancay, superan en escala a Chavín de Huántar. Algunos investigadores han asumido, prematuramente, que Chavín de Huántar fue simplemente un ejemplo más de un fenómeno más amplio de centros monumentales construidos debido al incremento poblacional y al mejoramiento de las prácticas agrícolas (S. Pozorski y S. Pozorski 1987). Las excavaciones en estos grandes centros han producido materiales que sugieren que estos centros cívico-ceremoniales fueron principales -o solamente importantes- al interior de sus propios valles, teniendo un impacto muy tenue fuera de éstos (S. Pozorski y T. Pozorski 1987, 2008). En Casma, múltiples centros, cada cual con complejos piramidales de una escala impresionante, sugieren la presencia de dos o más entidades políticas, mientras que las investigaciones en el valle de Lurín (costa central) indican que cada uno de los ocho complejos piramidales en forma de «U» pudieron haber servido como el centro de pequeñas entidades políticas autónomas (Burger y Makowski 2009; Burger y Salazar 2008). En estos centros costeños del Periodo Inicial, la ausencia de una clara especialización artesanal y otros índices de una sociedad fuertemente estratificada con una bien desarrollada élite, contrasta con la impresión causada por la escala monumental de su arquitectura. Esta aparente paradoja se hace más comprensible cuando uno se da cuenta que muchos, y quizás todos, los centros monumentales son el resultado de una acumulación de siglos de eventos constructivos.

Ahora parece que la primera transformación pan-regional de los Andes centrales ocurrió durante el primer milenio antes de Cristo con la emergencia de la esfera de interacción Chavín. Si se consideran fechados radiocarbónicos calibrados, este fenómeno empezó alrededor del 1000 a.C. y continuó hasta alrededor del 300 a.C. Desafortunadamente, el Hallstatt Plateau ocurrió entre el 800 y el 400 a.C. por lo que los fechados radiocarbónicos que caen en este lapso de tiempo son especialmente poco confiables (Higham and Higham 2009, van der Plicht 2004, Zietseva et al. 2005). Basándonos en medidas disponibles de C14, el fenómeno Chavín parece empezar alrededor de dos siglos antes del Hallstatt Plateau y continua al menos un siglo después de éste. Así, en términos de cronología absoluta, los fechados actuales de Chavín encajan bien con los estimados de Heggarty y Beresford-Jones sobre la expansión inicial de la familia lingüística aymara.

Se ha escrito mucho sobre el «Horizonte Chavín» y sería poco práctico revisar aquí toda la evidencia. Sin embargo, es importante enfatizar que este fenómeno es complejo y que envuelve un conjunto de fuerzas ideológicas, económicas y sociales (Burger 1988; 1992; 1993; 2008). Esto incluye: 1. La propagación de un culto religioso probablemente bajo la forma de una red de oráculos en la costa y sierra del Perú; 2. La emergencia de un patrón de peregrinaje desde la costa, sierra y los flancos orientales andinos hacia el centro de Chavín de Huántar; 3. El crecimiento del centro cívico-ceremonial de Chavín de Huántar hasta convertirse en un centro protourbano con una extensión de 50 hectáreas con varios miles de residentes; 4 . Un incremento en el comercio a larga distancia a lo largo y ancho de la esfera de interacción facilitado por el uso de caravanas de llamas; 5. La emergencia de elites sociopolíticas en Chavín de Huántar, así como, centros políticos autónomos como Kuntur Wasi y Pacopampa y el establecimiento de la interacción entre entidades políticas pares (peer-polity) y sus elites, probablemente, a través del intercambio de bienes suntuarios y alianzas matrimoniales; 6 . La propagación de tecnologías metalúrgicas, textil y otras nuevas tecnologías, algunas de las cuales estuvieron asociadas con la producción de emblemas para la elite o parafernalia de culto; y finalmente 7. La adopción de formas y decoración de cerámica compartidas por parte de grupos distantes de Chavín de Huántar que, previamente, habían producido distintos estilos de cerámicas locales. Algunos investigadores 
que están principalmente familiarizados con el registro arqueológico de la costa norte, no han podido reconocer el impacto revolucionario de la esfera de interacción Chavín debido a que sus investigaciones se han centrado en áreas fuera de su alcance. Por otra parte, el énfasis que estos investigadores asignan a la escala de los edificios y otras particularidades arquitectónicas les ha conducido a obviar o subestimar los radicales cambios que se dieron en la organización social y en la interacción a larga distancia durante el Horizonte Temprano (e.g. Haas 2010; Pozorski y Pozorski 2008).

En tanto la vigencia temporal de la esfera de interacción Chavín parece encajar bien con la postulada expansión del aymara central durante el Horizonte Temprano, también fue contemplada por Heggarty y Beresford-Jones, la posibilidad que una «cronología larga» de la expansión pueda encajar entre el final del Horizonte Temprano y los inicios del Intermedio Temprano. Sin embargo, esta posibilidad teórica parece encontrar poco sustento en el registro arqueológico. Como reacción al colapso de Chavín de Huántar y otros centros de la esfera de interacción Chavín, aparentemente, hubo un incremento en la violencia social y una disminución en el intercambio a larga distancia en la mayor parte del territorio del centro y norte del Perú. La mayoría de los grupos culturales se volvieron cada vez más peculiares buscando distanciarse de sus vecinos, así comenzó el patrón de diversidad cultural que caracteriza al periodo Intermedio Temprano. Afortunadamente, se ha venido dando una oleada de investigaciones en muchas de estas culturas y no es una exageración decir que, sorpresivamente, hubo poca interacción entre ellas. Así, Yayno, cerca de Pomabamba, el principal centro Recuay tuvo un escaso contacto, si hubo alguno, con culturas costeñas tales como Moche o Lima (George Lau, comunicación personal). Del mismo modo, a pesar del incremento de la muestra de restos culturales de Nazca y Moche temprano de la costa sur y norte del Perú, respectivamente, casi no hay evidencia alguna de intercambio o comunicación entre ambos. Esto no significa que el intercambio o comunicación a larga distancia despareció por completo, pero sí hubo una marcada disminución en la interacción panregional, así como, en la integración cultural (o económica) cuando lo comparamos con las etapas temprana o media del Horizonte Temprano.

Aún no se entiende completamente la extensión geográfica de la esfera de interacción Chavín, sin embargo, recientes investigaciones están confirmando que ésta alcanzó Collúd en la cuenca del Lambayeque en la costa norte, Congona y Pacopampa en la sierra norte de Cajamarca, Ingatambo y Huayurco en la selva del flanco oriental de los Andes cerca de la frontera con el Ecuador (Alva 2010; Seki et al. 2006; Yamamoto 2010; Watanabe 2010; Clasby y Meneses 2013). Igualmente, el límite sur de la esfera de interacción Chavín ha sido extendido como resultado de investigaciones recientes en la última década. Las investigaciones hechas por Reindel, Isla y Kaulicke han documentado influencia Chavín en un componente Paracas temprano en la cuenca del río Nazca (Isla y Reindel 2006). Como en Ica, incluye indiscutible iconografía y elementos estilísticos Chavín tanto en su cerámica como en sus textiles. Del mismo modo, el trabajo de Yuichi Matsumoto y Yuri Cavero han develado un templo Chavín sobre el pueblo de Vilcashuamán, unos $100 \mathrm{~km}$ al sur de la moderna ciudad de Huamanga (Matsumoto y Cavero 2010). Este complejo en forma de «U» incluye no sólo un portal hecho de piedra cortada parecido al de Chavín, sino también una plaza rectangular hundida y una galería de mampostería de piedras similar a las de Chavín de Huántar. Su parafernalia ritual tiene rasgos similares y, en al menos un caso, idéntico a los artículos ceremoniales encontrados en Chavín de Huántar. Notablemente, la influencia de Chavín en la arquitectura del templo y en la iconografía antecede a la adopción de rasgos estilísticos chavinoides en el estilo de la cerámica local. La ubicación de Campanayuq Rumi es comprensible dada la ubicación de la principal cantera de obsidiana usada por Chavín de Huántar, la fuente de Quispisisa, ubicada a 100 kilómetros al sur de Vilcashuamán (Burger y Glascock 2000). Hasta el momento no se ha encontrado evidencia de la esfera de interacción Chavín al sur en Apurímac o Cusco.

Sin embargo, debe enfatizarse que incluso dentro del área nuclear la esfera de interacción Chavín no fue ni continua ni fija en su extensión. Parecería haber algunas áreas en Perú, tales como la región de Otuzco-Huamachuco-Santiago de Chuco en la sierra norte, que se resistieron a participar en esta 
red de interacción, mientras que hay otras, como los valles bajos de Santa, Casma y Nepeña que participaron en la esfera de interacción Chavín entre la parte final del Periodo Inicial y los comienzos del Horizonte Temprano, pero que más tarde se retiraron de ella y desarrollaron un patrón cultural radicalmente diferente durante la mitad Horizonte Temprano (Proulx 1985; Burger 2003; Chicoine 2006). A pesar de la complejidad de este patrón distribucional, puede ser potencialmente compatible con la expansión inicial del aymara central a nivel linguística.

\section{LA TENTACIÓN DE UNA SÓLIDA HIPÓTESIS SOBRE LA DISPERSIÓN DE LA LENGUA}

A pesar de la posible relación de la esfera de interacción Chavín con la expansión inicial del aymara central en términos de espacio y tiempo, queda un enigma en el marco conceptual de Heggarty y Beresford-Jones. Tal como indican en su publicación (2010) ellos creen que la expansión de la lengua debe ser explicada en términos de un número limitado de factores, empezando con fuerzas demográficas, culturales y políticas y como última explicación favorecen un modelo de dispersión agriculturalenguaje. Para los Andes centrales y durante el Horizonte Temprano, postulan que consistió de un paquete agrícola basado en el cultivo de maíz. A pesar que reconocen que el maíz parece haber sido introducido relativamente tarde en la dieta centroandina, argumentan que éste proporcionó el componente necesario en «la conyuntura de un paquete particular [de cultivos] que podrían propulsar la expansión de una lengua en una escala demográfica y territorial grande». Con igual seguridad declaran: «Solamente alrededor de la empieza del Horizonte Temprano, nosotros arguimos, finalmente se cruzó este umbral [agrícola], gracias sobre todo a la incorporación completa de un un cereal como cultivo [maíz] por fin» (Heggarty y Beresford-Jones 2010: 189, traducción del autor). El problema es que la evidencia arqueológica disponible sugiere que el maíz no fue un alimento básico en la esfera de interacción Chavín ni parece haber sido el crucial componente perdido de la dieta temprana de la costa y sierra peruana.

Heggarty y Beresford-Jones reconocen que su posición no encaja bien con el consenso general entre los arqueólogos andinistas pero argumentan que esto se debe a un sesgo de los andinistas en la interpretación de la información disponible. Afirman que «Un desequilibrio existe en la manera que andinastas perciben la importancia relativa de maíz y tubérculos en sustener poblaciones andinas durante la prehistoria, un desequilibrio que apoya mas en dogma ideológica que en evidencia arqueobotánica verdadera». (Heggarty y Beresford-Jones 2010, suplemento A, p. 6). Desafortunadamente, pese a que la retórica de este argumento es convincente, también es errónea. Como anotan, el eminente antropólogo John Murra escribió un influyente ensayo en el que argumentó que la dieta basada en tubérculos y granos cultivados en altura proporcionó la alimentación básica para las poblaciones serranas durante el periodo Inca y que el maíz fue un cultivo ceremonial cuya importancia dietética fue exagerada por los cronistas españoles (Murra 1960).

En la última década, la postura de Murra, basada en una revisión crítica de documentos históricos españoles y en un detallado conocimiento de la etnografía andina moderna, ha sido debilitada por una serie de estudios químicos en restos óseos enfocados en el análisis de los índices de carbones estables de muestras arqueológicas de Junín (Hastorf 1990; Hastorf y Johannessen 1993, 1994), Ancash (Burger y Van der Merwe 1990) y Cuzco (Burger et al. 2003). Estos estudios concluyeron que el maíz fue un alimento básico en estos tres lugares del imperio Inca. Hastorf y otros han argumentado, asimismo, que los cambios en los patrones de asentamiento y modificaciones en la infraestructura apoyan la hipótesis del incremento del maíz Inca como cultivo básico del Tawantinsuyo. Un ejemplo dramático de este proceso ha sido documentado en una investigación histórica sobre la cuenca del Cochabamba (Wachtel 1982). Debe tomarse nota que ninguno de los investigadores citados han tenido dificultad en rechazar el «dogma ideológico» promovido por Heggarty y Beresford-Jones debido a las claras evidencias. Por ejemplo, un estudio sobre la química de los huesos humanos de Machu Picchu concluyó: 
«Los resultados de Machu Picchu, vistos particularmente en asociación con aquellos de Jauja y Waman Wain, sugieren que bajo la administración Inca el maíz fue mucho más que un cultivo ritual de gran prestigio. Parece haberse convertido en el alimento principal de la dieta, opacando a la papa y otros alimentos andinos ricos en C3. El dominio de maíz en la vida diaria de estos individuos parece que se extendió en los Andes Centrales durante el Horizonte Tardío» (Burger et al. 2003: 135-136).

Si hay un dogma que continúa influenciando la arqueología andina, es la presumida asociación del maíz con las civilizaciones andinas tempranas. Esta idea viene siendo popular por más de medio siglo, mucho antes que sea evaluada con evidencia arqueológica (e.g. Collier 1961). La impresión que el maíz debió haber cumplido un rol crucial en la propagación de la civilización temprana andina parece derivar, en parte, de la perspectiva tradicional en la que el maíz tuvo un rol central en la dieta de las civilizaciones mesoamericanas prehispánicas, así como el rol fundamental que jugaron los cereales en los sistemas agrícolas de las civilizaciones del Viejo Mundo (Burger y Van der Merwe 1990). Pero la situación dietética en los Andes centrales fue fundamentalmente distinta de la mesoamericana y del Viejo Mundo. En los Andes, hubo una amplia gama de cultivos alimenticios disponibles para el consumo como el resultado de un largo proceso de domesticación de cultígenos nativos en la costa, sierra y en la selva tropical (Pearsall 1992, 2008). En los Andes centrales, estos alimentos, con un alto rendimiento nutricional y calórico, fueron suplementados por una rica fuente de proteínas proveniente de recursos marinos y mamíferos domesticados.

En el caso de la esfera de interacción Chavín el tema de subsistencia todavia está bajo discusión. Al parecer, la dieta en la sierra durante el Horizonte Temprano fue dominada por tubérculos nativos de altura (como papas [Solanum tuberosum], oca [Oxalis tuberosa] y ollucos [Ullucus tuberosus]; pseudocereales de altura tales como quinua [Chenopodium quinoa] y kiwicha [Amarantus caudatus]) y lupinos (tarwi [Lupinus mutabilis]), todos ellos naturalmente adaptados a las alturas y a los empinados terrenos de los Andes. Una fuente principal de proteínas durante el Horizonte Temprano fue la carne de dos animales domesticados: la llama y la alpaca, criaturas que igualmente estuvieron bien adaptadas a los pastizales de la sierra alta o puna del Perú que se inicia a $3800 \mathrm{msnm}$. En la costa hubo un amplio rango de cultivos ricos en carbohidratos y otros elementos nutricionales que estuvieron mejor adaptados a bajas alturas, estos productos dominaron la dieta. Muchos de ellos fueron domesticados en la cuenca amazónica, en los flancos orientales de los Andes o incluso en la sierra, pero crecieron satisfactoriamente en las tierras irrigadas de los valles costeños medios y bajos. Estos cultivos incluyen camotes [Ipomoea batatas], yuca [Manihot esculenta], achira [Canna edulis], maní [Arachis hypogaea], variedades de zapallos [Cuburbita ficifolia, Cucurbita maxima, Cucurbita maschata], varios tipos de frijoles, [Canavalia plagiosperma, Phaseolus lunatus, Phaseolus vulgaris], y varias frutas incluyendo guaba [Psidiumgua java], pacae [Inga Feuillei], chirimoya [Annona cherimolia] y palta [Persea Americana] (Pozorski 1983; S. Pozorski y T. Pozorski 1987; Pearsall 1992, 2008). Gracias a las excelentes condiciones de preservación de la árida costa peruana, en los basurales han sido recuperadas muestras macro botánicas de la mayor parte de estos cultivos y en cantidades sustanciales (e.g. Cohen 1979; Pozorski 1983). Los tubérculos y las raíces alimenticias están poco representados entre los restos macro botánicos, aunque en algunas ocasiones han sido registrados (Ungent et al. 1981). Afortunadamente, los restos de estos alimentos están bien representados en los estudios de residuos de almidón hallados en vasijas para cocción de la costa central y norte del Perú.

Se debe enfatizar que, a diferencia de Mesoamérica que carece de los grandes animales domesticados y los ricos recursos marinos encontrados en los Andes, no hubo la necesidad nutricional de basar la dieta en el maíz, para alcanzar los niveles de proteínas básicas u otros requerimientos nutricionales básicos. Además, los habitantes prehistóricos de los Andes centrales tomaron ventaja de las heladas nocturnas en las punas para desarrollar un proceso de secado al frío de tubérculos y carne para producir chuño y charqui respectivamente. Este proceso de secado al frío permitió el almace- 
namiento de los tubérculos y carne procesados por más de un año. Se hicieron avances similares en la costa para la producción de pescado y moluscos secos usando sal marina y exponiéndolos al sol. Los productos deshidratados eran más livianos y ocupaban menos espacio, por lo tanto fue más fácil transportarlos así que en su estado natural. De este modo, estos alimentos procesados tuvieron mucho de las mismas ventajas atribuidas por Heggarty y Beresford-Jones al maíz. Existe evidencia arqueológica que sugiere que la producción de chuño y pescado seco existió en el Periodo Inicial y que la producción de charqui de llama estuvo en marcha durante el Horizonte Temprano (Miller y Burger 1995; Víctor Vásquez, comunicación personal).

En contraste con los alimentos andinos discutidos arriba, hay consenso que el maíz fue domesticado en el oeste de México en la región del río Balsas a partir de una grama silvestre (teosinte) y que fue introducido en los Andes centrales como un cultivo relativamente primitivo (Pearsall 2008). Al principio no se adaptó bien a las altas elevaciones, las pendientes pronunciadas, a las heladas nocturnas de invierno o las frecuentes granizadas que caracterizan a los Andes centrales. El maíz fue además particularmente sensible a los impredecibles patrones de lluvias comunes en la sierra. Dado el reducido tamaño de su parte comestible y la dificultad para cultivarlo, no sorprenden los escasos restos de maíz en los sitios arqueológicos anteriores al Horizonte Temprano.

A pesar de la aparente rareza en el consumo de maíz durante el tercer y segundo milenio antes de Cristo, existe evidencia arqueológica que hubo un amplio conjunto de alimentos para mantener el crecimiento de una densa población. Los trabajos recientes en los valles de Supe, Huaura y Pativilca indican que esta fue la situación para el Precerámico Tardío (Haas y Creamer 2006; Shady 2006) e, igualmente, existe evidencia contundente de un sólido crecimiento de la población durante el Periodo Inicial en los valles de Lurín, Moche y Casma - en la costa central y norte- entre grupos que consumieron muy poco maíz (S. Pozorski y T. Pozorski 1987; Billman 2001; Burger y Salazar 2008). El crecimiento en el número y tamaño de los sitios arqueológicos constituye evidencia convincente de una ocupación intensivo en las secciones medias y bajas de la mayor parte de la costa peruana antes de la esfera de interacción Chavín.

Aunque la casi ausencia de consumo de maíz fue originalmente inferida a partir del estudio de los restos macro botánicos en el valle de Lurín (Umlauf 2009), esto se ha confirmado con análisis de isotopos estables de carbón (Tykot et al. 2006). Los análisis en isotopos estables de carbón es una técnica diseñada para determinar la cantidad relativa de alimentos con C4 consumidos comparados con los alimentos que contienen C3. En los Andes, el maíz fue el único alimento con C4 en la dieta debido a que, como se ha indicado anteriormente, fue domesticado a partir de una grama subtropical en México. Todos los demás alimentos consumidos en los Andes centrales son de plantas con C3 (Burger y Van der Merwe 1990). En el valle de Lurín, muestras tomadas de cabello humano bien preservado del sitio Mina Perdida y de huesos del sitio contemporáneo de Cardal indican que el maíz no jugó un rol importante en la dieta local (Tykot et al. 2006: 189-195, Tabla 14-1). Dada la evidencia de Lurín y de otros sitios de la costa peruana, no hay necesidad para sugerir que fue necesario un cambio al consumo preferencial de maíz para completar un paquete agrícola adecuado para conducir una expansión demográfica asociada a la agricultura, debido a que se puede demostrar que ha ocurrido en varios lugares de la costa peruana antes que se extendiera la popularidad del maíz.

La falta de una necesidad nutricional para una dieta basada en maíz no significa que otros factores no hayan propiciado su relevancia como alimento, como aparentemente ocurrió en tiempos Inca. Así, para evaluar la hipótesis de Heggarty y Beresford-Jones es fundamental buscar la evidencia arqueológica y determinar la escala en el consumo de maíz durante el Horizonte Temprano al interior de la esfera de interacción Chavín. Dado el poder analítico de estudiar los isótopos estables de carbono para abordar esta pregunta, debería dársele un peso particular para tales estudios, en contraste a la evidencia macrobotánica. Afortunadamente, se han llevado a cabo análisis de isótopos de carbono en muestras de varios centros de la sierra que participaron de esta esfera de interacción: Chavín de 
Huántar (3150 msnm), Pacopampa (2140 msnm) y Kuntur Wasi (2300 msnm). Adicionalmente, también se analizaron muestras de otros centros de la sierra como Huacaloma (2800 msnm) en la cuenca de Cajamarca; este centro parece haber tenido una conexión más débil con la esfera de interacción Chavín que los otros sitios. Las primeras muestras estudiadas provienen del mismo sitio de Chavín de Huántar. Se analizaron muestras de la fase Urabarriu (1000-800 cal a.C.) y la fase (Janabarriu (700-300 cal a.C.). La fase Urabarriu se considera como del periodo del Templo Viejo, mientras que la fase Janabarriu corresponde al Templo Nuevo. Las muestras de los contextos de la fase Urabarriu $(n=4)$ oscilaron entre $-18,7 \%$ a a $-19,0 \%$ mientras que la única muestra de la fase Janabarriu midió $-18,1 \%$. Estas cifras implican que el maíz fue consumido en pequeñas cantidades, estando lejos de ser un alimento principal. Por ejemplo, un grupo de yanacona (un sirviente perpetuo vinculado a un linaje real) en Machu Picchu, quien tuvo una dieta basada en maíz, arrojó medidas ( $n=59)$ con una media de -11,9\%. La conclusión de los análisis de Chavín de Huántar fue que el maíz fue un cultivo secundario dentro de la dieta diaria dominada por plantas C3 como la papa (Burger y Van der Merwe 1990).

Los estudios de isótopos de carbono en los huesos humanos de Chavín de Huántar plantearon la pregunta de si el maíz pudo haber jugado un papel más importante en los centros de la sierra más al norte, donde a menor altitud se pudo realizar mejor su cultivo. Dada esta duda, fue de particular interés un segundo estudio en huesos humanos de una muestra de El Mirador, un área residencial ubicada al este de Pacopampa, un centro importante en la esfera de interacción Chavín. Las muestras (n=10) tomadas de las excavaciones dirigidas por Daniel Morales en una residencia fechando al fin del Periodo Inicial aproximadamente contemporáneo con la fase Urabarriu, arrojó mediciones en un rango de $-18,4 \%$ o a $-19,6 \%$ o con un promedio de $-19,3 \%$. Estos resultados fueron sorpresivamente cercanos a los de Chavín de Huántar, a pesar de la baja elevación y el clima húmedo, y una vez más apuntaron a indicar que el rol del maíz fue solo el de un cultivo secundario en la dieta de Pacopampa (Tykot et al. 2006: 188-189, 193-194, Tabla 14-1). Un tercer estudio llevado a cabo por Yuji Seki y Minoru Yoneda (2005) encontró que las muestras de tanto los contextos del Periodo Inicial (i.e. Fase Huacaloma Temprano) $(n=5)$ como los del Periodo Inicial tardío (i.e. Huacaloma Tardío) $(n=6)$ del sitio de Huacaloma en el valle de Cajamarca mostraron un consumo mínimo de maíz, con una mayoría de muestras arrojando un promedio alrededor de $-23 \%$, un panorama que sugiere incluso un consumo de maíz menor en relación al sitio de Pacopampa y Chavín de Huántar (Seki y Yoneda 2005: Fig. 14).

También, se analizaron muestras de tres fases del sitio de Kuntur Wasi, otro centro famoso de la esfera de interaccion Chavín, ubicado en el valle alto del Jequetepeque: Fase Kuntur Wasi (800-500 cal a.C.) y la Fase Copa (500-250 cal a.C.). Las muestras de la fase Kuntur Wasi $(n=8)$ variaron de $-23 \%$ a $-18 \%$, mientras que las muestras de la subsecuente fase Copa $(n=14)$ variaron principalmente entre $-23 \%$ a $-18 \%$ aunque una sola muestra arrojó aproximadamente -17\%. Estos resultados confirmaron que, desde una perspectiva dietética, en Kuntur Wasi el maíz fue poco más que un cultivo secundario durante el periodo Chavín. Como en Chavín de Huántar, existen algunos indicadores que su consumo se incrementó ligeramente durante el Horizonte Temprano pero sin llegar a ser un alimento importante (Seki y Yoneda 2005: Fig. 14). En resumen, los datos de los isótopos de carbono de tres de los principales centros de la esfera de interacción Chavín sugieren que el maíz no fue un componente crucial en los sistemas agrícolas que sostuvieron dichos sistemas socioeconómicos. Sin embargo, la representación de maíz en botellas de cerámica fina recuperadas en el sitio de Chavín de Huántar y en Kotosh, sugieren que el maíz ya tenía una importancia simbólica mayor que su rol nutricional durante la parte tardía del Periodo Inicial (Burger y Van der Merwe 1990).

Los resultados de isótopos de carbono en las muestras del Periodo Inicial temprano del sitio de Huacaloma y las muestras del Precerámico Tardío de Huaricoto en el Callejón de Huaylas (Burger y Van der Merwe 1990) implican que el maíz ya estaba consumiéndose aunque a una escala muy baja antes de la aparición de la esfera de interacción Chavín. Así, el cultivo de maíz en la sierra no debería malinterpretarse como el resultado de la emergencia de la civilización de Chavín. 
La evidencia empírica aquí presentada parece ser suficiente para rechazar la hipótesis de la dispersión del lenguaje por la agricultura del maíz; no obstante, es útil examinar la evidencia aducida por Heggarty y Beresford-Jones (2010, ver en línea el Suplemento A) para sostener su argumento. Heggarty y Beresford-Jones empiezan por hacer una serie de afirmaciones sin fundamento argumentando que el maíz es más robusto y variable en diferentes ambientes en relación a los tubérculos. Este es un argumento muy débil dada la enorme variabilidad de tubérculos andinos y su adaptación a un amplio rango de ambientes y fluctuaciones climáticas. En tanto que se desarrollaron muchas variedades de maíz en los Andes, nunca alcanzaron la notable diversidad de papas (e.g. existen alrededor de tres mil variedades en el Perú). En sus esfuerzos por encausar a la humilde papa, los autores culpan a la hambruna irlandesa de la papa (1845-1852) por esta supuesta carencia de diversidad. Aparentemente, los autores no se dan cuenta que fue específicamente la ausencia de una diversidad genética de papas traídas al Viejo Mundo desde los Andes y cultivadas en Irlanda lo que las hizo tan vulnerables a las plagas. Si los irlandeses hubieran tenido la diversidad genética de los campesinos tradicionales andinos (El Centro Internacional de la Papa reportó que un campesino aymara cultivaba 2000 variedades en sus campos), definitivamente la plaga no hubiera ocurrido en los niveles observados. Irónicamente, Heggarty y Beresford-Jones también repiten afirmaciones exageradas sobre las ventajas del maíz en base a un refutado artículo escrito por David Wilson (1981). Este artículo intentó probar que la arquitectura monumental del periodo Precerámico Tardío fue producto de una agricultura basada en el cultivo de maíz; cuando fue publicado este artículo fue considerado defectuoso (para una perspicaz refutación ver: Quilter y Stocker 1983). Tres décadas de investigación han probado que el argumento de Wilson referente al rol que jugó el maíz en la economía de subsistencia del Precerámico Tardío de la costa es un error.

La evidencia arqueológica más reciente que, Heggarty y Beresford-Jones citan para sustentar su argumento es limitada y, en algunos casos, malinterpretada. Notaron que en la síntesis sobre la agricultura andina temprana escrita por Deborah Pearsall (Tabla 7.1) el maíz «es completamente ausente hasta el Periodo Inicial pero aparece repentinamente como presente o abundante en todos los sitios del Horizonte Temprano en la lista» (Heggarty y Beresford-Jones 2010: suplemento p.5). Un examen de esta tabla, sin embargo, revela que de los cinco sitios listados, cuatro pertenecen al Horizonte Temprano medio o tardío y están ubicados en los valles bajos de Casma, Virú y Supe. Como anotamos anteriormente, esta porción de la costa no participó en la esfera de interacción de Chavín durante este periodo por lo que la popularidad del maíz en estas economías de subsistencias no pueden ser utilizadas para explicar el éxito o expansión del fenómeno Chavín. El quinto sitio, Las Aldas, es mostrado por Pearsall en tabla 7.1 por tener una cantidad moderadamente abundante de maíz durante 1040-895 a.C., pero esta lista es inconsistente con el reporte de las excavaciones citado por Pearsall (Pozorski y Pozorski 1987). Los Pozorski afirman sin ambigüedad: «Las Haldas en tiempos post-templo, Pampa Rosario, y San Diego fue acompañado por la introducción de maíz al valle de Casma-no gradualmente pero repentinamente» (Pozorski y Pozorski 1987: 119); la ocupación post-templo en Las Aldas es contemporánea con Pampa Rosario, que fue ocupado alrededor 700-300 a.C. Así, los sitios citados por Pearsall demuestran que el maíz no se convirtió en un cultivo popular en esta área de la costa hasta que este se distanció de la esfera de interacción Chavín.

El único otro sustento arqueológico que Heggarty y Beresford-Jones ofrecen para su hipótesis de la dispersión del lenguaje en base al cultivo del maíz en la sierra es la propuesta de Brian Finucane en su artículo «Maiz y complejidad sociopolítico en el valle de Ayacucho, Perú» en el que sustenta que sus resultados de isótopos de carbón «sugieren que maiz había vuelto el componente más importante en la dieta humana en el valle de Ayacucho no mas tarde que 800 a.C.» (Finucane citado en Heggarty y Beresford-Jones 2010: 189). Una revisión detallada en el artículo de Finucane, sin embargo, revela que está conclusción es basada en los isótopos de carbono de Rosamachay y Pikimachay. La Tabla 1 de este artículo indica que fueron analizados sólo tres muestras de huesos de estas dos cuevas (Finucane 2009: 538). Las tres muestras fueron fechadas por un acelerador de espectrometría de masas (AMS). 
La única muestra de Rosamachay arrojó una fecha de 259-423 d.C y las dos muestras de Pikimachay arrojó fechados de 131-323 d.C y 552-806 a.C. (Finucane 2009: 539). Así, según estas medidas, dos de las muestras de huesos fechadas datan del Periodo Intermedio Temprano y no nos pueden decir nada sobre la dieta durante el Horizonte Temprano. Así, la conclusión de Finucane citada por Heggarty y Beresford-Jones está basada en el análisis de un solo hueso que viene de un nivel inmediatamente debajo de otro conteniendo la muestra del Periodo Intermedio Temprano; además, esta fecha cae dentro del Hallstatt Plateau y, por lo tanto, es menos confiable que lo indicado en la Tabla 1. Pero aún si esta medida fuera precisa, es cuestionable que podamos alcanzar cualquier conclusión sobre la dieta del Horizonte Temprano en Ayacucho basados en los restos de un solo individuo enterrado en una remota cueva. Dado el tamaño de la muestra $(\mathrm{n}=1)$ y las dudas sobre el contexto se debe tomar con mucha cautela y escepticismo la propuesta de Finucane sobre el consumo de maíz durante el Formativo.

En conclusión, en la medida que el fenómeno Chavín contiene muchos aspectos, no se puede establecer una simple correlación entre Chavín y un particular producto agrícola principal como el maíz. Por el contrario, la adopción del maíz como un producto alimenticio principal parecería haber ocurrido después del colapso de Chavín y la propagación de la irrigación agrícola parece anteceder este cultivo (Burger y Van der Merwe 1990; Tykot et al. 2006). Del mismo modo, no existe una correlación entre la expansión de la esfera de interacción de Chavín y una tecnología agrícola en particular como la irrigación. En el caso de la irrigación, hay evidencia creciente que precede a Chavín por varios milenios. Así, el fenómeno Chavín no constituye el tipo de «fuerza histórica» que Heggarty y Beresford-Jones querían usar para explicar la dispersión pan-regional de la lengua.

Mientras que Heggarty y Beresford-Jones se enfocaron en la relación entre la agricultura y la propagación de la lengua, otros se han concentrado en otras «fuerzas históricas» tales como la guerra y migración. Sin embargo, vale notar que no existe evidencia que la expansión de la esfera de interacción Chavín estuviera asociada con guerras o conquistas armadas. Mientras que la guerra puede ser difícil de identificar arqueológicamente, existen varias líneas de evidencia que pueden sugerir el incremento de su importancia basadas en la ubicación de los sitios en lugares defensivos, la presencia de elementos arquitectónicos con ventajas militares (muros externos concéntricos, parapetos, entradas indirectas, puntos restringidos de acceso, etc.), armas (e.g. macanas, concentraciones de piedras para hondas) y un incremento de restos óseos humanos con indicadores osteológicos de violencia (Topic y Topic 1987; Arkush y Stanish 2005; Tung 2007a, 2007b). Es significativo que ninguno de estos elementos asociados con guerra intensiva haya sido documentado dentro de la esfera de interacción Chavín (Burger 1992: 225). En contraste, todos estos elementos se vuelven prominentes algunos siglos después de la caída de la esfera de interacción Chavín y el abandono del centro panregional de Chavín de Huántar. Algunas de estas características se pueden dar durante la fase final de la declinación de Chavín, pero sólo en la costa norcentral, un área marginal a la esfera de interacción Chavín (Ghezzi 2006; Topic y Topic 1978; Wilson 1988).

Asimismo, no existe evidencia de movimientos poblacionales asociados a la expansión de la influencia Chavín. Rafael Larco y recientemente Yoshio Onuki sugirieron que el desarrollo de los centros prominentes de la sierra que fueron parte de la esfera de interacción Chavín pueden haber sido el resultado de migraciones de grupos costeños, tales como aquellos responsables de la cultura Cupisnique, a la sierra e, igualmente, Onuki (2001) ha propuesto que algunos de los líderes de Kuntur Wasi pudieron ser de la costa. En tanto que esta idea es interesante, no está sustentada por los análisis de carbón y nitrógeno publicados sobre las tumbas de Kuntur Wasi (Seki y Yoneda 2005). Tampoco los materiales culturales más tempranos recuperados en Chavín de Huántar sugieren un origen costeño de su población (Burger 1984). Podría considerarse la posibilidad que la expansión de los elementos Chavín pueda haber estado asociada a movimientos poblacionales pero es escasa la evidencia pertinente. El primer estudio diacrónico de ADN arqueológico enfocado en la costa sur del Perú, incluye la península de Paracas y las cuencas de los ríos Ica y Nazca. Esta zona es relevante debido a que fue una 
zona importante de la esfera de interacción Chavín. Significativamente, Fehren-Schimitz et al. (2010) no encontraron indicadores de migraciones poblacionales durante el Horizonte Temprano o el Periodo Intermedio Temprano; tales movimientos recién se identifican durante el Horizonte Medio.

Esta revisión de los factores involucrados en la esfera de interacción Chavín presenta a Heggarty y Beresford-Jones y sus seguidores como un enigma. Si el fenómeno Chavín proporciona la única posibilidad temporal y espacial adecuada para la expansión del aymara central, es difícil aferrarse a las «fuertes» hipótesis explicativas tradicionales tales como la expansión agrícola, guerra y/o movimientos de población, como las explicaciones para la expansión de esta lengua, dado que estos procesos son inconsistentes con el registro arqueológico. Si la correlación con la esfera de interacción Chavín es correcta, parecería implicar que otros procesos no considerados tradicionalmente por los lingüistas históricos pueden haber sido responsables de la expansión de la lengua.

\section{COSMOPOLITISMO Y LA EXPANSIÓN DE LA LENGUA}

¿Cuál pudo haber sido el proceso responsable de la expansión de la lengua aymara central?. Es posible imaginar un escenario en el cual los factores mencionados anteriormente como los responsables de la esfera de interacción Chavín podrían haberse combinado para crear una situación propicia para la dispersión rápida y extensiva de la lengua? Dada la historia del judaísmo, el islamismo y el catolicismo romano es razonable sugerir que la irradiación de un culto religioso panregional como Chavín podría haber ocurrido en conjunción con un lenguaje sagrado. Como el estudioso Benedict Anderson observa: un lenguaje sagrado usado para los textos sagrados y las oraciones unifica a gente de diferentes historias lingüísticas y étnicas (Anderson 1991: 12). Mientras que en el caso de Chavín tal lenguaje sagrado no habría estado asociado a un texto en particular, sí pudo estar asociado a expresiones de un complejo iconográfico, como los hallados en los textiles de Carhua (Cordy-Collins 1976; Burger 1988). Estos objetos, como las pinturas sobre seda brocada conocidas como thangkas para los tibetanos, pueden haber resumido el sistema cosmológico Chavín, expresado en textos sagrados memorizados y transmitidos oralmente. La propagación de este lenguaje sagrado (digamos, el aymara central para seguir con el argumento) vía funcionarios religiosos conectados con oráculos satélites alejados de Chavín, se vería reforzada por la experiencia de los creyentes llegados de estas áreas distantes quienes hacían el peregrinaje al centro de Chavín de Huántar, donde fue utilizado dicho lenguaje. Si el uso del aymara como una «lengua sagrada», eventualmente, se expandió para servir como una lingua franca para transacciones de intercambio y/o para negociaciones sociales entre las elites al interior de la esfera de interacción Chavín, su impacto habría sido aún mayor (Burger 2013). Aunque el aymara central pudo haber sido introducido como un idioma de alto estatus entre los especialistas religiosos y la elite en un entorno multilingüe, finalmente se habría convertido atractivo para aquellos que buscaban adoptar una identidad más cosmopolita y, por lo tanto, se habría diseminado en la sociedad, particularmente si recibió sustento de la élite local.

El modelo hipotético que acabamos de describir no es consistente con los modelos de la expansión del lenguaje con los cuales estamos más familiarizados, pero al menos es consistente con la evidencia arqueológica existente. Además, debe reconocerse que las ideas populares sobre la dispersión del lenguaje están fuertemente influenciadas por la experiencia de la civilización occidental, particularmente aquella de los siglos recientes, un periodo de tiempo dominado por estados poderosos y coercitivos. Cuando lidiamos con la expansión de un lenguaje que precede a la emergencia de estados poderosos y es posterior a la expansión de una agricultura expansiva, podría ser necesario considerar nuevos tipos de modelos, como el que proponemos aquí. Este sesgo explicativo de varios lingüistas históricos ha sido reconocido por el experto en sánscrito Sheldon Pollock, quien ha tratado de proveer una perspectiva más equilibrada desarrollando una explicación histórico-comparativa del cosmopolitismo que existió en un pasado más distante. De particular interés aquí es su tratamiento sobre del cosmopolitismo sánscrito, una formación cultural transregional que existió en la mayor parte de Asia 
del sur y en mucho de Asia del sureste entre el 300-1300 d.C. (Pollock 1996: 197). Comenzando como un lenguaje sagrado en un ambiente sacerdotal, el sanscrito emergió gradualmente en la mayor parte de esta extensa área como una lengua política pública con la cual las élites expresaron su poder no en términos de asuntos materiales sino en términos de poder estético. Así, la propagación del sánscrito a través de los límites étnicos, ecológicos, y lingüísticos ayudó a «establecer un nuevo tipo de zona de interacción cultural, que algunos podrían llamar un ecumene [oikoumene]» (Pollock 1996: 199). La dispersión del lenguaje y el proceso de transculturación en el funcionamiento del sánscrito cosmopolita no dependieron del poder militar, el Estado, o el aparato legal o administrativo. Pollock escribe que «La creación de una forma de discurso lingüisticamente homogéneo y conceptualmente casi estandardizado parece de haber ocurrido como una forma de globalización premoderno». Pollock observa que el escenario para esto fue establecido por los esfuerzos de pequeños grupos de comerciantes, aventureros y religiosos profesionales. No hay evidencia que alguna vez estuvieron sobre el tapete iniciativas estatales a gran escala o que tomó lugar algo remotamente parecido a la «colonización». Pollock escribió «Ningunas ligas de subordinación política resultó, ningúna dependencia material, o explotación, ningunos asentamientos deomgraficamente significantes, ninguna conquista militar» (Pollock 1996: 217). En su mayor extensión, el sánscrito se extendió sobre una zona enorme desde lo que es hoy en día Afganistán hasta Java y desde Nepal a Sri Lanka. Pollock hace una pregunta no menos válida para Chavín de lo que es para el sánscrito cosmopolita: «Como podemos entender los procesos por lo cual estratos sociales enteros estaban listos de abandonar sus rutinas linguísticas y doxa y submitir de libre voluntad a una nueva cultura» (Pollock 1996: 232).

Pollock contrasta la propagación del sánscrito con la irradiación del latín, que viajó como el lenguaje de un estado conquistador así como fue también el lenguaje de un esfuerzo misionero para la expansión del cristianismo. A diferencia del sánscrito, la propagación del latín fue centralizada y militarizada, y la coerción fue, en gran medida, parte de su introducción. Como el latín, el sánscrito cosmopolita también fue creado por acción, pero no las acciones de un estado conquistador. En su caso fue hecho por la circulación de mercaderes, literatos, religiosos profesionales y aventureros independientes. Coerción, cooptación, control jurídico, e incluso persuasión no son evidentes en ninguna parte. Aquellos que participaron en la cultura del sánscrito cosmopolita optaron por hacerlo así y podían elegir hacerlo de esa forma (Pollock 2000: 603).

No hay razón para asumir que un Chavín cosmopolita pudiera haber sido idéntico al sánscrito cosmopolita descrito por Pollock. Sin embargo, sugeriría que las condiciones creadas por el fenómeno Chavín pueden ser consideradas como compatibles con una propagación panregional o transregional de la lengua, primero en su capacidad de lengua sagrada asociada a la cosmología y la religión y posteriormente a roles adicionales en la cultura tales como la interacción de las elites y su presentación. Vale notar dos elementos del modelo de Pollock que se puede ser relevante al caso de Chavín. El primero es la forma en la que una visión del mundo cosmopolita puede ser crucial para el proceso de la propagación de una lengua. El gran número de artefactos foráneos recuperados en Chavín de Huántar a lo largo de la historia del templo confirma una atmósfera cosmopolita sin precedentes en el sitio. Esto es ejemplificado por el hecho que un $30 \%$ de la cerámica utilizada tanto en el templo como en los alrededores del asentamiento parece ser de origen foráneo (Druc 1998) y que muchas ofrendas almacenadas tales como las que se hallaron en la Galería de las Ofrendas y la Galería de las Caracolas fueron hechas casi exclusivamente con materiales exóticos cuyos puntos de origen abarcan la costa norte, la costa central y los flancos orientales peruanos así como las costas de Ecuador (Lumbreras 1993; Burger 2013). La fusión de elementos arquitectónicos foráneos y los estilos iconográficos no locales precisamente entregan el mismo mensaje (Burger 1992). No es coincidencia que en una de las últimas representaciones esculturales de la deidad principal de Chavín (algunas veces conocidas como la Piedra Medusa), el/ella es representado(a) sosteniendo las conchas del Spondylus y el Strombus, ambas oriundas de las aguas cálidas de la costa ecuatoriana. 
El descubrimiento que la banda este del río Mosna frente al templo estuvo cubierto por viviendas pertenecientes a los pobladores del sitio incrementa la extensión mínima del asentimiento antiguo a aproximadamente 50 hectáreas. Esta es una estimación conservadora, debido a que la mayor parte del área de la ocupación ahora está enterrada bajo varios metros cúbicos de rocas y deslizamientos de tierra. Sin embargo, mi estimación de la población original de 2000 a 3000 residentes, ahora parece ser más razonable que cuando fue hecha (Burger 1984: 247). Más importante, esta población muestra evidencia de diferenciación en términos de estatus social y especialización ocupacional (Burger 1984, 2008; Burger y Miller 1995). Ningún otro centro poblado en el Perú del Horizonte Temprano parece haber sido tan grande o más complejo. Así, al interior de su entorno cultural transregional, Chavín de Huántar habría sido un centro cosmopolita excepcionalmente grande y sofisticado donde sus residentes, así como, los peregrinos y mercaderes de todos los Andes centrales, habrían estado en contacto entre ellos. Como hemos indicado, no existieron centros comparables en los periodos Precerámico Tardío (Arcaico) o el Periodo Inicial. De hecho, incluso durante el Periodo Intermedio Temprano (AD 100-600), no hay sitio que sea equivalente a su amplitud cosmopolita. Mientras que Cahuachi en la costa sur y el sitio de huacas de Moche en la costa norte son impresionantes centros con una arquitectura masiva, estos parecen haber servido a una audiencia regional en lugar de a una transregional, encarnando tradiciones culturales locales en vez de trascenderlas.

Un segundo punto señalado por Pollock que merece mayor consideración es su afirmación que el cosmopolita sanscrito se expandió por la consiente y voluntaria decisión de grupos locales para moverse más allá de sus tradiciones culturales ancladas en el espacio local, para poder participar en una manera que trascienda la geografía y el lenguaje local. Esto no necesariamente conlleva el rechazo de las tradiciones locales sino que supone la introducción de nuevos elementos y la creación de nuevas prioridades. En la medida que estos sentidos que involucran voluntad y conciencia son difícilmente identificables arqueológicamente, podría ser significativo que durante el Horizonte Temprano hubo una aceptación generalizada de los elementos estilísticos Chavín en la cerámica a lo largo y ancho de su esfera de influencia (Burger 1988, 1992, 1993). Dado que generalmente la cerámica fue producida localmente y usada principalmente en contextos domésticos, las decisiones de producción y consumo podrían reflejar la voluntad de la gente en una manera que otras clases de artefactos no pueden. Incluso en tiempos Inca, la cerámica local de consumo doméstico en la mayor parte de las áreas, fue lenta en incorporar elementos Inca en los estilos locales, inclusive en áreas que fueron dominadas militar y políticamente (Menzel 1959; Morris y Thompson 1985). Podemos interpretar que los patrones de cerámica durante el Horizonte Temprano están representando un interés generalizado de las comunidades locales en participar de una forma más amplia, que trascienda algunos de los provincialismos de las identidades locales. La adopción de una nueva lengua para ser usada en contextos especiales puede haber sido parte de este proceso.

Un aspecto que finalmente debe considerarse es la cronología. ¿Cuán largo fue la duración del fenómeno Chavín y acaso fue este tiempo suficiente para crear las condiciones para la propagación de una lengua sagrada como el aymara central? Esta pregunta se complica por un conjunto de fechados problemáticos de Chavín de Huántar debido a la perturbación en la zona de la arquitectura monumental del templo (Burger 1981) y ha sido exacerbada por los problemas en interpretar las medidas de C14 en la época en que el radiocarbono estuvo fluctuando en la atmósfera. Una revisión reciente de los fechados disponibles de Chavín de Huántar y sitios relacionados me han conducido a modificar mis estimaciones originales de las fases de Chavín, que estuvieron basadas en fechados sin calibrar. Ahora situaría el establecimiento de Chavín de Huántar en aproximadamente 1000 cal a.C. y el abandono del complejo del templo y su asentamiento asociado en aproximadamente $300 \mathrm{cal}$. A. C. La fase inicial de la ocupación del sitio, la fase Urabarriu, estima una duración de 1000 cal. a.C. al 800 cal a.C., mientras que la fase Chakinani se estima ahora en un lapso de 800-700 cal a.C. La fase Janabarriu fue probablemente más larga de lo que originalmente creímos y puede haber durado del 700 cal a.C. al 300 cal a.C. con la mayor parte de sus resultados cayendo dentro del Hallstatt Plateau. 
Ahora existe evidencia que a lo largo de sus siete siglos de historia, el centro de Chavín tuvo conexiones dinámicas con grupos que se extendían desde la sierra norte de Cajamarca, los flancos orientales de Jaén y las lejanas costas de Lambayeque, hasta la sierra sur de Ayacucho y las adyacentes costas de la cuenca del río Nazca. En resumen, la escala de tiempo y la escala espacial del fenómeno Chavín, si bien es menos masivo que aquel del latín o el sánscrito, es suficientemente extenso para explicar la dispersión de una de las principales lenguas de los Andes centrales. Ademas, no existió otro fenómeno transregional comparable al ocurrido tanto antes o después del Horizonte Temprano que ofrece una alternativa viable.

\section{ARQUEOLOGÍA, DISPERSIÓN DE UNA LENGUA Y LA EVALUACIÓN DE UNA HIPÓTESIS}

Un esfuerzo general por estudiar la dispersión de la lengua a través de la colaboración de la arqueología y la lingüística histórica, es necesario y que las «fuerzas históricas» deberían examinarse para explicar el ritmo y la extensión de estas dispersiones. Mientras algunos arqueólogos pueden sentirse incómodos con los intentos de ajustar el registro arqueológico al modelo lingüístico propuesto, tengo la esperanza que éste y otros esfuerzos similares estimularán trabajos futuros para evaluar el modelo aquí propuesto. El estudio de los topónimos será crucial para evaluar el modelo y son necesarios estudios toponímicos más detallados en todos los valles costeños y serranos, particularmente, dada la actual alteración de la agricultura y el conocimiento tradicional del paisaje. Si Chavín fue la fuente para la dispersión del aymara central debería reflejarse en los patrones donde los topónimos aymara y quechua aparecen o no. Igualmente, son cruciales estudios detallados adicionales de las divergencias dentro de las diferentes lenguas en las familias lingüísticas del aymara y el quechua, particularmente, si pueden asociarse a investigaciones toponímicas.

Chavín no fue un fenómeno homogéneo. Algunas áreas como las sierras entre Quiruvilca y Cajamarca, nunca parecen haber participado de él (Burger 1992; Pérez 1998); presumiblemente, estas áreas mostrarían un patrón distinto de topónimos aymara en relación a aquellas que fueron incorporadas en la cosmopolita o ecuménica Chavín. Igualmente, muchos de los valles bajos entre Virú y Huarmey, particularmente en Casma y Nepeña, inicialmente jugaron un rol importante en la esfera de interacción Chavín en sitios como Cerro Blanco y Huaca Partida, pero las poblaciones de esta área finalmente optaron por salirse de ella luego del 700 cal a.C. (Burger 2003; Chicoine 2006; Ikehara y Shibata 2008; Proulx 1985). Una vez más, puede esperarse que esto tenga un impacto en la dispersión del lenguaje y reflejarse en la distribución de los topónimos aymara.

Finalmente, en tanto que se han esclarecido los límites norte y sur de la esfera de interacción Chavín (o Chavín ecuménico o Chavín cosmopolita), debemos esperar fisuras equivalentes en la forma que se planteó la expansión y la diversificación de los principales lenguajes andinos. En el norte, debería esperarse que los topónimos aymara extendieran una frontera porosa corriendo desde Lambayeque a Pacopampa y Jaén y, luego, más al norte éstos deberían decrecer notablemente. Igualmente, en el sur, deberíamos esperar que la distribución de los topónimos aymara central deberían extender una frontera porosa que va, de manera general, de la cuenca del Nazca a las sierras sur de Ayacucho. Obviamente, diversos factores históricos incluyendo despoblamientos y recolonización puede haber impactado en la supervivencia de los topónimos, pero estas fuerzas históricas pueden ser tomadas en consideración en la evaluación crítica de patrones toponímicos locales. Siguiendo el colapso del mundo Chavín al final del Horizonte Temprano, la mayor parte de las áreas volvieron más aislados y provinciales. Se ha reportado un incremento en la violencia en muchas áreas, junto con una fuerte caída en el intercambio y consumo de bienes exóticos durante este periodo que duró, aproximadamente, entre el 300 a.C. y el 200 d.C. En algunos casos, los estilos cerámicos locales se reafirmaron mientras que en otros casos fueron introducidos estilos nuevos para reemplazar al estilo «internacional» Chavín. El periodo entre el 200-700 d.C. es también un periodo de desarrollo relativamente insular en la mayor parte del Perú (Lau 2006: 162) y en culturas como la Nazca, Lima, Moche, Recuay y Cajamarca, 
esto se expresa en limitados movimientos a larga distancia o intercambio focalizado en el área o región inmediata. Podría esperarse que estos siglos que abarcan el final del Horizonte Temprano y el Periodo Intermedio Temprano hayan fomentado la diferenciación en la lengua que se expandió como parte del fenómeno Chavín.

¿Qué tan bueno es el ajuste, cuando la información lingüística se evalúa en relación a la evidencia arqueológica? Si es pobre, debería considerarse la posibilidad que la arqueología sea incompleta o incomprendida antes de rechazar el modelo de dispersión lingüística. Por ejemplo, si los topónimos aymara central aparecen en la costa al sur de Nazca, debería contemplarse la posibilidad que la esfera de interacción Chavín se expandió en esta área. Esta nunca ha sido intensivamente estudiada y, por lo tanto, no puede desestimarse. Proporciono este ejemplo hipotético en parte para sugerir como es que la interacción entre la lingüística histórica y la arqueología podrían dar lugar, en el futuro, a valiosos trabajos arqueológicos de campo. En tanto que los esfuerzos actuales para explicar la dispersión de las principales lenguas en los Andes pueden ser frustrantes, es importante recordar que estos vacilantes y torpes primeros pasos van a estimular una nueva ola de investigaciones que darán los elementos necesarios para una explicación más completa y convincente de la propagación prehistórica del aymara y el quechua. Si no entramos en este discurso, es probable que el actual estado de abandono de este importante tema vaya a continuar en el siglo XXI.

\section{Agradecimientos}

Mi agradecimiento especial a Barney Bate por exponerme el trabajo de Sheldon Pollock, a Jason Nesbitt, Jeffrey Quilter y Lucy Salazar por ayudarme a pulir mis ideas sobre este tópico y a Paul Heggarty y David Beresford-Jones por sus estimulantes ideas, O.Gabriel Prieto B. por la traducción al español y a Victor Falcón Huayta por la revisión del manuscrito. 


\section{BiBLIOGRAFÍA}

ALVA, Ignacio

2010 «Los complejos de Cerro Ventarrón y Collud-Zarpán: de Precerámico al Formativo en el valle de Lambayeque». Boletin de Arqueología PUCP 12: 97-117.

ANDERSON, Benedict R.

1991 Invented Communities. NY: Verso Press.

ARKUSH, E. y C. STANISH

2005 «Interpreting conflict in the ancient Andes: implications for the archaeology of warfare». Current Anthrology 46(1): 3-28.

BELLWOOD, Peter

2005 First Farmers. The Origins of Agricultural Societies. Blackwelll Publishing, Malden, MA

BENFER, Robert, Jr., Bernadino OJEDA, Neil DUNCAN, Larry ADKINS, Hugo LUDEÑA, Miriam VALLEJOS, Víctor ROJAS, Andres OCAS y Gloria REAL

2010 «La tradición religioso-astronómico en Buena Vista». Boletín de Arqueología PUCP 11: 53-102.

BILLMAN, Brian R.

2001 «Understanding the timing and tempo of the evolution of political centralization on the Central Andean coastline and behond». En J. Hass (ed.), In From Leaders to Rulers, pp. 177-204. NY: Kluwer Academic.

BURGER, Richard L.

1981 «The radiocarbon evidence for the temporal priority of Chavin de Huantar». American Antiquity 46(3): 592-602.

1984 The Prehistoric Occupation of Chavin de Huantar, Peru. University of California Publications in Anthropology 14. University of California Press, Berkeley.

1985 «Concluding remarks: early Peruvian civilization and its relation to the Chavin horizon». En C. Donnan (ed.) Early Ceremonial Architecture in the Andes, pp. 269-289. Washington, D.C.: Dumbarton Oaks Research Library and Collection.

1988 «Unity and heterogeneity within the Chavin horizon». En: R. Keatinge (ed.) Peruvian Prehistory, pp.990144. Cambridge: Cambridge University Press.

1992 Chavin and the Origins of Andean Civilization. Londres: Thames and Hudson Ltd.

1993 «The Chavin horizon: stylistic chimera or socioeconomic metamorphisis?». En: D. Rice (ed.) Latin American Horizons, pp. 41-82. Dumbarton Oaks Research Library and Collection.

2008 «Chavin de Huantar and its sphere of influence». En: H. Silverman y W. Isbell (eds.) Handbook of South American Archaeology, pp. 681-703. Berlín: Springer.

2013 "In the Realm of the Incas: An Archaeological Reconsideration of Household Exchange, Long-distance Trade, and Marketplaces in the Pre-Hispanic Andes». En: K. Hirth y J. Pillsbury (eds.) Merchants, Markets and Exchange in the Pre-Columbian World, pp. 319-334, Washington D.C.: Dumbarton Oaks Research Library and Collection.

BURGER, Richard L. y Michael D. GLASCOCK

2000 «Locating the Quispisisa obsidian source in the Department of Ayacucho, Peru». Latin American Antiquity 11(3): 258-268.

BURGER, Richard L., Julia A. LEE-THORP y Nikolaas J. VAN DER MERWE

2003 «Rite and Crop in the Inca State Revisited: An Isotopic Perspective from Machu Picchu and Beyond». En: R.L. Burger y L.C. Salazar (eds.) The 1912 Scientific Expedition Collections from Machu Picchu: Human and Animal Remains, pp. 119-137. Yale University Publications in Anthropology 85, New Haven: Peabody Museum.

BURGER, Richard L. y Krzysztof MAKOWSKI

2009 Arqueología del Período Formativo en la Cuenca Baja de Lurín, Lima: Fondo Editorial PUCP, Lima. 
BURGER, Richard L. y Lucy C. SALAZAR

2008 «The Manchay culture and the coastal inspiration for highland Chavin civilization». En: W.J. Conklin y J. Quilter (eds.), Chavin Art, Architecture and Culture, pp.85-105. Monograph 61, Los Ángeles: Cotsen Institute of Archaeology, University of California.

BURGER, Richard L. y Nikolaas VAN DER MERWE

1990 «Maize and the origin of highland Chavin civilization: an isotopic perspective». American Anthropologist 92(1): 86-96.

CAMPBELL, Lyle y Terence KAUFMAN

1976 «A linguistic look at the Olmec». American Antiquity 4(1): 80-89.

CERRON-PALOMINO, R.

1998 «Examen de la teoría aimarista de Uhle». En: P. Kaulicke (ed.) Max Uhle y el Perú Antiguo, pp.69-84. Lima: Fondo Editorial PUCP.

2000 Lingüística aimara. Cusco: Centro Bartolomé de las Casas.

2003 Lingüística quechua. Cusco: Centro Bartolomé de las Casas.

CHICOINE, David

2006 «Early Horizon Architecture at Huambacho, Nepeña Valley, Peru». Journal of Field Archaeology 31(1): $1-22$.

CLASBY, Ryan y Jorge MENESES

2013 «Nuevas investigaciones en Huayurco: Resultados iniciales de las excavaciones de un sitio de la ceja de selva de los Andes peruanos». Arqueologia y Sociedad 25: 303-326. Lima: UNMSM.

COLLIER, Donald

1961 «Agriculture and Civilization on the Coast of Peru». En: J. Wilbert (ed.) The Evolution of Horticultural Systems in Native South America: Causes and Consequences, pp.101-109. Caracas: Editorial Sucre.

CORDY-COLLINS, Alana

1976 An Iconographic Study of Chavin Textiles from the South Coast of Peru: the Discovery of a Pre-Columbian Catechism. Unpublished Ph.D. dissertation, Archaeology Department, University of California, Los Angeles.

DRUC, Isabel

1998 «Ceramic Production and Distribution in the Chavin Sphere of Influence (North-Central Andes)». BAR International Series 731. Oxford.

FEHREN-SCHMITZ, Lars, Markus REINDEL, Elsa TOMATO y Susanne HUMMEL

2010 «Pre-Columbian population dynamics in coastal southern Peru.» American Journal of Physical Anthropology 141: 208-221.

FINUCANE, Brian

2009 «Maize and socio-political complexity in the Ayacucho Valley». Current Anthropology 50: 535-545.

GHEZZI, Ivan

2006 «Religious warfare at Chankillo». En: W. Isbell y H. Silverman (eds.) Andean Archaeology III, pp. 67111.

HAAS, Jonathan

2010 «Comments». Current Anthropology 51(2):185185-186.

HAAS, Jonathan and Winifred CREAMER

2006 «Crucible of Andean civilization: the Peruvian coast from 3000 BC to 1800 BC». Current Anthropology 47: 745-775.

HEGGARTY, Paul y David BERESFORD-JONES

2010 «Agriculture and language dispersals: limitations, refinements, and an Andean exception?» $\mathrm{Cu}$ rrent Anthropology 51(2): 163-191.

HINGHAM, C. y T. HINGHAM

2009 «A new chronological framework for Southeast Asia,based on a Bayesian model from Ban Non Wat». Antiquity 83: 144. 
IKEHARA, Hugo y Koichiro SHIBATA

2008 «Festines e integración social en el Periodo Formativo: nuevas evidencias de Cerro Blanco, valle bajo de Nepeña». Boletín de Arqueología PUCP 2005: 123-159.

ISLA, Johny y Markus REINDEL

2006 «Evidencias de culturas tempranas en los valles de Palpa, costa sur del Perú». Boletín de Arqueología PUCP 10: 285-304.

JUSTESON, John y Terence KAUFMAN

1993 «A decipherment of epi-Olmec hieroglyphic writing». Science 259: 1703-1711.

LAU, George

2006 «Northern exposures: Recuay-Cajamarca boundaries and interaction». En: W. Isbell y H. Silverman (eds.) Andean Archaeology III, pp.143-170. Springer, NY

LUMBRERAS, Luis Guillermo

1993 Chavín de Huántar: Excavaciones en la Galería de las Ofrendas. Materialen zu Allgemeinen und Vergleichenden Archaeologie Band 51. Verlag Phillip von Abern, Main am Rhein.

MATSUMOTO, Yuichi y Yuri CAVERO

2010 «Una aproximación cronológica del centro ceremonial de Campanayuq Rumi, Ayacucho». Boletin de Arqueología PUCP 13: 313-346.

MENZEL, Dorothy

1959 «The Inca occupation of the south coast of Peru». Southwestern Journal of Anthropology 15(2): 125142.

MIDDENDORF, Ernst

1959 [1891] «Prólogo a Die Aymará Sprache». En: Las Lenguas aborígenes del Perú, Parte II, pp. 56-102. Lima: UNMSM.

MILLER, George R. y Richard L. BURGER

1995 «Our father the cayman, our dinner the llama: Animal utilization at Chavin de Huantar, Peru». American Antiquity 600(3): 421-458.

MORRIS, Craig y Donald THOMPSON

1985 Huanuco Pampa: An Inca City and Its Hinterland. Londres: Thames and Hudson, LTD.

ONUKI, Yoshio

2001 «Cupisnique en la sierra de Cajamarca». Arqueológicas 25: 67-81.

PEARSALL, Deborah M.

1992 "The origins of plant cultivation in South America». En: C.W. Cowan y P.J. Watson (eds.) The Origins of Agriculture: An International Perspective, pp. 173-205. Washington D.C.: Smithsonian Institution Press.

2008 «Plant domestication and the shift to agriculture in the Andes». En: H. Silverman y W. Isbell (eds.) Handbook of South American Archaeology, pp.105-120. Berlín: Springer.

PEREZ, Ismael

1998 «Sitios del Periodo Formativo en Santiago de Chuco, departamento de La Libertad, sierra norte de los Andes Centrales». Boletín de Arqueología PUCP 2:127-145

POLLOCK, Sheldon

1996 «The Sanskrit Cosmopolis, 300-1300: Transculturation, vernacularization and the question of ideology». En: J.E.M. Houben (ed.) Ideology and Status of Sanskrit, pp.197-247. Leiden: E.J.Brill.

2000 «Cosmopolitan and vernacular in history». Public Culture 12(3): 591-625.

POZORKSI, Shelia y Thomas POZORSKI

1987 Early Settlement and Subsistence in the Casma Valley, Peru. Iowa City: University of Iowa Press.

2008 «Early cultural complexity on the coast of Peru». En: H. Silverman y W. Isbell (eds.) Handbook of South American Archaeology, pp. 607-631. Berlín: Springer.

POZORSKI, Thomas y Shelia POZORSKI

1987 «Chavin, the Early Horizon and the Initial Period». En: J. Haas, S. Pozorski y T. Pozorski (eds.) The Origins and Development of the Andean State, pp. 36-46. Cambridge: Cambridge University Press. 
PROULX, Donald

1985 An Analysis of the Early Cultural Sequence in the Nepeña Valley, Peru. Research Report Number 25, Department of Anthropology, University of Massachusetts, Amherst.

QUILTER, Jeffrey

1985 «Architecture and chronology at El Paraíso, Peru». Journal of Field Archaeology 12: 279-297.

QUILTER, Jeffrey y Terry STOCKER

1983 «Subsistence economies and the origin of Andean Complex Societies». American Anthropologist 85: 545-562.

RENFREW, Colin

1987 Archaeology and Language: the Puzzle of Indo-European Origins. London: Jonathan Cape.

ROWE, John Howland

1950 «Sound patterns in three Inca dialects». International Journal of American Linguistics, 16: (3): 137-148, julio. Baltimore.

1953 «Eleven Inca prayers from the Zithuwa ritual». Kroeber Anthropological Society Papers 8-9: 82-99. Berkeley.

1954 «Linguistic classification problems in South America». En: Papers from the Symposium on American Indian Linguistics held at Berkeley, July 7, 1951. University of California Publications in Linguistics, vol. 10, pp. 13-26. Berkeley and Los Angeles.

SANTILLANA, Julian I.

1999 «Andenes, canales y paisaje». En: Los Incas: Arte y Símbolos, pp.61-108. Lima: BCP.

SEKI, Yuji, Walter TOSSO, Juan Pablo VILLANUEVA y Kinya INOKUCHI

2006 «Proyecto arqueológico Pacopampa '05: Avances y correlaciones regionales». Arqueología y Sociedad 17: 149-178. Lima: UNMSM.

SEKI, Yuji y Minoru YONEDA

2005 «Cambios de manejo del poder en el formativo: desde el análisis de la dieta alimenticia». Perpsectivas Latinoamericanas 2: 110-131. Japan.

SHADY, Ruth

2006 «La Civilización Caral: sistema social y manejo del territorio y sus recursos». Boletín de Arqueología PUCP 10: 59-90.

TELLO, Julio

1913 «Algunas conexiones gramaticales de llas lenguas Campa, Ipurina, Moxa, Baure, Amuesha, Goajijira, del grupo o familia Arawak o Maipuro». Revista Universitaria 1:506-532. Lima

1917 «Folklore indiano: leyenda de génisis de los Amueshas». Revista de Psiquiatriía y Disciplinas Conexas 1(2): 51-55. Lima

1942 «Origen y desarollo de las civilizaciones prehistóricas». Actas del XXVII Congreso de Americanistas (1939). Lima: Imprenta Gil.

TOPIC, John y Theresa LANG TOPIC

1997 «Hacia una comprensión de la guerra andina». En: R, Varón y J. Flores (eds.) Arqueología, Antropología, e Historia en los Andes, pp.567-590. Lima: IEP.

1978 «Prehistoric fortification systems of northern Peru». Current Anthropology 119: 618-619.

TORERO, Alfredo

1974 El quechua y la historia social andina. Lima: Universidad Ricardo Palma.

1984 «El comercio lejano y la difusión del quechua. El caso de Ecuador». Revista Andina 4: 367-389.

TUNG, Tiffany

2007a «From corporeality to sanctity: treansforming bodies into trophy heads in the prehispanic Andes». En: R. J. Chacon y D.H. Dye (eds.) The Taking and Displaying of Human Trophies by Amerindians, pp. 477-500. Springer Press.

$2007 \mathrm{~b}$ «Trauma and violence in the Wari empire of the Peruvian Andes: warfare, raids, and ritual fights». American Journal of Physical Anthropology 133(3): 941-956. 
TYKOTT, Robert, Richard L. BURGER y Nikolaas VAN DER MERWE

2006 «The importance of maize in the Initial Period and Early Horizon Peru». En: J.E. Staller, R.H. Tykot y B.F. Benz (eds.) Histories of Maize, pp.187-197. Londres: Academic Press.

UHLE, Max

1910 «La posición histórica de los aymaras en el antiguo Perú». Boletín de la Oficina Nacional de Estadística VI: 58-60, 350-356. La Paz.

UMLAUF, Marcelle

2009 «Restos botánicos de Cardal durante el Periodo Inicial». En: R. Burger y K. Makowski (eds.) Arqueologia del Periodo Formativo en la Cuenca Baja de Lurín, pp. 95-110. Lima: PUCP.

UNGENT, Donald, Shelia POZORSKI y Tom POZORSKI

1981 «Prehistoric remains of sweet potato from the Casma Valley of Peru». Phytologia 49:401-415.

VAN DER PLICHT, J.

2004 «Radiocarbon, the calibration curve and Scythian chronology». En: E.M. Scott, A. Alekseev y G. Zaitseva (eds.) Impact of the Environment on Human Migrations in Eurasia, pp.45-61. NY: Kluwer Academic Publishers.

WACHTEL, Nathan

1982 «The mitmas of the Cocabamba Valley: the colonization policy of Huayna Capac». En: G. Collier, R. Rosaldo and J. Wirth (eds.) The Inca and Aztec States, 1400-1800: Anthropology and History, pp. 199-235. NY: Academic Press.

WATANABE, Shinya

2010 «Dos monolitos del sitio de Congona, sierra norte del Perú». Boletin de Arqueología PUCP 10: 53-67.

WILLIAMS, Carlos

1985 «A scheme for the early monumental architecture of the Central Coast of Peru». En: C. Donner (ed.) Early Ceremonial Architecture in the Andes, pp. 227-240.

WILSON, David

1981 "Of maize and men: a critique of the Maritime Hypothesis of state origins on the coast of Peru». American Anthropologist 83: 93-120.

1988 Prehistoric Settlement Patterns in the Lower Santa Valley, Peru. Washington DC: Smithsonian Institution Press.

YAMAMOTO, Atsushi

2010 «Ingatambo: un sitio estratégico de contacto interregional en la zona norte del Peru». Boletín de Arqueología PUCP 12: 25-52.

ZIETZEVA, G.I., K.V CHUNGUNOV, MN.A. BOKOVENKOI, V. I. DERGACHEV, V.G. DIRKSEN, B. VAN GEEL, M.A. KOULKOVAI, L.M. LEBEDEVA, A.A. SEMENTSOV, J. VAN DER PLICHT, E.M. SCOTT, SS. VASILIEV, K.I. LOKHOV y N. BOUROVA

2005 «Chronological study of archaeological sites and environmental change around $2600 \mathrm{bp}$ in the Eurasian stepe belt (uyuk Valley, Tuva Republic)». Geochronometrica 24: 97-107. 